\title{
12. Dwelling with Moving Images
}

\author{
Miriam De Rosa
}

\begin{abstract}
Some filmmakers or artists decide to put art at the heart of their creation, applying not only the relationship between cinema and art to their concept but also to various aspects of the process of creation. Miriam De Rosa addresses this kind of "art contemporary turn" by examining the different incursions of cinema from the point of view of the contemporary art space: "how the contemporary experience of moving images is articulated when it enters art spaces." The presence of film in this foreign space, transforming it into a different and personalized place, can be observed in recent exhibitions: SLEEPWALKers (2007); Marta Minujín's Mesunda Reloaded (2019) at the New Museum in New York; and Sensitive Environments by the Milan-based collective Studio Azzurro.
\end{abstract}

Keywords: Space, exhibition, environments

Moving image production and reception practices at the time of "postcinema" do not simply result from a process of increasing replacement of old modes of creation and consumption with new ones. In the era of "film as an experience" (Harbord 2002; Casetti 2015), much of the debate has been focusing on shifting definitions and revised categories moving across the territory of ontological enquiry (Friedberg 2000; Krauss 1999a, 1999b; Cherchi Usai 2001; Rodowick 2008; Aumont 2012; Gaudreault and Marion 2015 among others). In this chapter I shall contribute to such debate, attempting in fact to relaunch it further, beyond the constrains of medium specificity. To do so, I look in particular at how the contemporary experience of moving images

1 I would like to thank Wanda Strauven for championing my work, Greg de Cuir Jr. for his kind feedback on this text and Studio Azzurro for allowing me to include pictures of their work.

Chateau, D., and J. Moure. Post-cinema: Cinema in the Post-art Era. Amsterdam: Amsterdam University Press, 2020 DOI 10.5117/9789463727235_CH12 
is articulated when it enters art spaces, tangentially feeding the discourse about post-art, too.

Situating "post-cinema" in relation to the spatial turn in film studies (Connolly 2009; Rhodes and Gorfinkel 2011), I am interested in the contamination between cinema and art with regards to spectatorship and in particular in the ways in which the agency of spectators/visitors unfold. Moving from a phenomenological perspective the kind of moving image experience I look at is the one belonging to the subject - a subject that is embodied and embedded in space. Put it differently, the contemporary experience of moving images does not simply raise issues revolving around the increasingly algorithmic creation, distribution, recycling, remix and reordering of cinema but it poses the question of dwelling, that is, of how "post-cinema" (or new forms of cinema) is woven into the networked texture of everyday life and practices, of how it inhabits our space, and allows us inhabiting it through the image.

The increasing presence of moving images in gallery spaces is certainly not a new trend but, entering its second century, cinema is at the center of a process of interaction, at times integration, and exchange with a system of image consumption that does not only influence its language but powerfully impacts on it as a medium (Cowie 2009). Observing these dynamics from a slightly different point of view, art critic Nicholas Bourriaud coined the fortunate phrase "relational aesthetics" to describe precisely a kind of art that defines and constitutes itself in the act of opening outward, and in particular toward the public. If in the case of the art Bourriaud has in mind, "the exchanges that take place between people [...] turn out to be as likely to act as the raw matter for an artistic work" $(2002,37)$, cinema in the age of the "post-" also opens up, namely to a variability of modes of production, distribution, reception, subsequent elaboration and recycling, as well as to a myriad of possible formats. This reshuffles the relationship of moving images with other media, with themselves and their histories. Committing to a reflection on "post-cinema" is then a way to rethink moving images in light of a relational system based on the interconnections among processes, discourses, and disciplines.

Already in the 1960s and 1970s, but more systematically from the 1990s, "[f]ilm or filmic effects are so pervasive in the art world they have begun to reformat all kinds of other practices" (Foster 2003, 93). With the benefit of living some fifteen years after this statement was first shared, I would argue the situation is now possibly even more exacerbated: it is very rare not to encounter moving images in museums and art spaces, regardless of the content of the collection or the selection they exhibit. In fact, moving 
images do not enter art spaces only in the form of objects on display per $s e$, on the contrary they are employed according to various strategies that involve and insert them in the mechanics of galleries as dispositifs. We tend to forget or take it for granted because this is by now an entirely naturalized practice, but it is worth reminding how moving images in art spaces are not limited to the presence of artists' films or video installation projects. On a more procedural, technical, and subtler level screens and displays are used as digital signage tools that require the public to watch them. While this is certainly not comparable to the experience of watching a film or a video art work installed in the gallery, such an experience demands nonetheless a specific set of actions and establishes an equally specific set of expectations from the viewer. In other terms, a "screen-sphere" (Sobchack 2016) emerges in the art space implying a number of practices and establishing an economy of the attention that borrows from the etiquette and the mechanisms characterizing cinematic experience.

Looking more closely, what happens to the space where these dynamics unfold is that the introduction of screens and moving image-based tools in the museum build a sort of bubble that gathers the subjects around them and determines - albeit with a fairly wide range of possibilities - their attitudes and behaviors within the art space. Such bubble, such screen-sphere, might give the idea of a process informed after a centripetal force; however, this is not simply an inward-looking event that solely acts upon the interior of the museum. On the contrary, the same screening situation eliciting and favoring a viewing experience that is typical of cinema occurs when the museum space itself is remediated into a viewing surface which takes the pieces on display outward, allowing for an outward-facing distribution and consumption of the art that is otherwise only accessible once it overcomes the institutional and economical barriers that generally regulate the access to it. The examples in this instance are countless but works such as Doug Aitken's SLEEPWALKERS, commissioned by the MoMA in 2007 for its central Manhattan venue, are a case in point. Composed by five video pieces, the artwork has been installed taking advantage of the external walls of the museum building, both those facing the Sculpture Garden and those actually facing outward. This seemed to respond to a logic of extension and opening, whereby the moving image literally "made room for itself" discarding the binary interior/exterior, and re-designing the balance between the two, as well as the relationship between the private/institutional and the public spheres. As in a sort of reverse configuration, the gallery walls become in this case a double-sided surface for art - meaning by that Aitken's art film. They articulate a trajectory and provide an architecture to the public's visit at 
the museum if taken in their internal side, where they divide the exhibition space, articulating the path designed by the curators, and containing art. Contextually, however, the same walls work as outdoor screens too, making the artworks public, ${ }^{2}$ with no requirement to pay any tickets to watch the films, no indications of where to stand, sit or stop to have the best view of the screens, nor of the duration, temporal development, beginning or end point of the screening. ${ }^{3}$ All in all, these aspects contribute to metaphorically (but also very practically) show how the spread of moving images outside the classic cinematic precincts works, what challenges it poses and what the reactions of the public are.

As I have briefly mentioned, the reading of such processes that I shall argue for is one considering first and foremost the spatial element and the position of the entities situated in the space alongside the moving image. In this view, the subjects, as much as the moving image itself, have a power to practice and activate the space they are in. In the framework I am sketching, I propose to define this action on the space as design. This function is very often followed by a second action that puts into practice the concept offered by the overall design, whereby the space undergoes a disposition, that is, a rearticulation that functionally facilitates the design by establishing the conditions for it to move from a status of potentiality to one of reality. Worth specifying is also the impact of these processes on the definition of the environment where they unfold. I have thus far used the term space to mean the spatial extension where the subject, the moving image and any other entity is located. To be entirely precise, however, I would suggest to differentiate the environment taken in its neutral character and the practiced, lived environment once this is informed by the entities it contains, as it is rather incontestable that when an entity enters a certain environment this is marked by his presence. In line with phenomenology and more specifically with Martin Heidegger's philosophy of space (1971, 1993), I term the neutral environment space and the marked environment place. Now, the main difference between space and place is that, because marked by its presence and action, that is, by the design it informs around itself and the disposition it elicits, place is the specific space of an entity - the space where I live is "my place"; the space where I go see art pieces is a museum,

2 For reasons of space I cannot delve into a close analysis of SLEEPWALKERs, further details and visuals can however be found online. See https://www.moma.org/interactives/exhibitions/2007/ aitken/. Accessed August 20, 2019.

3 A rich literature addresses the characteristics of gallery films and their pattern of consumption. In the impossibility to provide a full overview on this, please see the key contributions in this area, such as Fowler 2004, 2011; Leighton 2008; Connolly 2009; Uroskie 2014. 
the place of art; the space where I watch a film is the place of cinema, and so forth. However, this categorization may be perceived as too rigid for our fast-paced, multitasking, hyper-flexible way of life. This is why positing a strictly ontological reading of the processes I am discussing is in my view not the most suitable: focusing on the presumed death, survival, second or virtual life of cinema and so on is too restrictive, to me the debate about "post-cinema" is an amazing opportunity to realize and acknowledge that the terms of the question shall change because the objects we are looking at already did. Shifting the attention from ontology to phenomenology and interdisciplinarity is the option I propose to take on.

The framework I am borrowing from Heidegger to do so, focuses on the conditions of not simply being but of being-there, that is, on a spatiallymindful horizon of existence which is articulated in direct response to space and time. While this relationality of sorts is not made explicit as such in the essays that constitute the base of the philosopher's thought on spatiality, I suggest it would indeed be of particular relevance for the development of the debate informing the current film studies, so as to put them in relation with other areas of the humanities and therefore to truly practice interdisciplinarity. Our contemporary moving-image forms mix up and mingle with other media configurations, therefore anticipating to grasp them by only adopting film studies tools is simply insufficient to offer an overview on "post-cinema" (not so to produce, for example, a solid close analysis of a film). Conversely, looking beyond the classic borders of the discipline is in my view an important move to mirror the historical moment we live in, a historical moment whereby "crisis" seems to be the keyword to interpret many phenomena to the extent that a quick online search of the term offers no less than 1,210,000,00o results in 0.73 seconds (Google, September 9, 2019). In such a historical moment "post-cinema" may easily be seen as an expression of the crisis of cinema, and this is precisely why situating the object of our inquiry in a broader space, understanding if and how it is interconnected with other entities, how it responds to this proximity and to the generalized regime of "ongoingness" that makes contemporary media increasingly fluid (Marchessault and Lord 2007; Marks 2012; Kim 2016), in what way it does unfold, morph, contaminate or strengthen its identity may suggest not a solution to the crisis but perhaps a realistic capture of the situation.

In Heidegger's system of thought, the main shift describing the passage from space to place is that by "gathering" the pure spatial extension around itself and making it suitable for its needs, making it - so to say - its "home," the entity inhabits the environment it is contained in. In other words, once 
space is entered, practiced by an entity, designed and disposed around it, place is founded and dwelling is possible. When articulating his framework, Heidegger had mostly in mind man as the entity activating space and turning it into place, but I believe the process well suits the mechanism in a broader fashion, this is why I suggest applying it, as I already anticipated, to any entity entering a certain space. In the conviction that, if anything, any entity has in itself a certain potential for action and that this is mirrored in the area around it, I mean to apply this scheme to the moving image. Better yet, design, dispose and dwelling are the three key processes that I argue can be applied to moving images as they enter art spaces. ${ }^{4}$ In this view, I shall contend that the experience of moving images at the time of "post-cinema" allows for a new sense of inhabitation of space, on the basis of a temporarily contamination and integration between image and space.

Coming back to Aitken's SLEEPWALKERS in light of this, what occurs on $5^{\text {th }}$ Avenue is that a street with its own characteristics and destination of use ceases to be only a space of transit, of motion, a way connecting point A to point $B$ or the back side of a major cultural institution, turning it into a place of viewing modeled after the presence, action and experience of moving images. A viewing situation, as transitory as it may be, is created, the design of a screen-sphere is set, and the elements articulating the situation are disposed so that this very design can be created and its ultimate function activated. Albeit only for the temporary duration of the screening, the viewer can dwell within this situation where moving images become part of the texture of the environment s/he lives in, practices and inhabits.

Of course, the variability of the setting mirrors, in turn, a high degree of variability of the situation resulting from the processes of design, disposition, and dwelling. Offering a taxonomy of situations exceeds the purposes of this reflection, but for the sake of exemplifying, the variability of moving-image configurations may well range from immersive, large-scale works such as Richard Mosse's INCOMING (2017), to interactive projects such as the audiovisual performance and digital environments by Refik Anadol (2008 onward), or, again, to the architectural quality of works that re-articulate the gallery space as in Stan Van der Beek's classic Movie Mural (1968) refashioned for

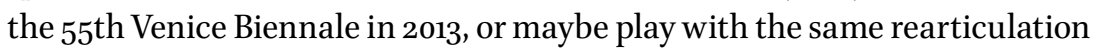

4 This does not apply to art spaces only. In Cinema e Postmedia: I territori del filmico nel contemporaneo (2013), that represents a first formulation of this argument eventually further developed in this chapter, I offer a wider overview of other possible real-life situations where the moving image triggers a number of mechanisms impacting on the spaces it enters so as to activate the processes I discuss here. 
of the gallery/movie theater nexus literally bringing the black box into the white cube as, notably, in Janet Cardiff and George Bures-Miller PARADISE Institute (2001). In all these as well as in other cases, a re-writing of art spaces is put into action in light of/by the presence of the moving image, allowing for an experience that is different from the classic film viewing as much as it is different from the traditional museum visit. In fact, cinema and art exchange visual and aural materials, languages, codes and formats mixing and borrowing from each other to create new configurations. ${ }^{5} \mathrm{As}$ Janet Harbord has observed in her study of contemporary film cultures,

the relationship of form and content, of mimesis and abstraction, becomes reconfigured through the different contexts of exhibition. What emerges is a binary of a different order: on the one hand a desire to maintain the purity of the singular object of the film text, and on the other, the dissolution of the film into a range of ancillary products in a context of consumption. Or, more simply, film as a discrete object or film as an experience. (Harbord 2002, 44-45)

Some fifteen years after Harbord, it is enough to observe our contemporary artistic moving images to discard a binary model (the film or the constellation of products emerging around it; the object or the experience it enables) in favor of a much more complex, multifaceted, fluid one. However, well in line with the idea effectively proposed by Harbord that the moving image as a component of a temporary configuration that enters a(-n art) space can be also understood in terms of experience, I shall also posit that when this happens a spatialization of moving images is favored. As a fiber of an organic whole, moving images weave into the environment becoming part of its texture, a component of that place, of that screen-sphere I have already introduced. They make room for themselves, activating an audio-visual regime which impacts on the behavior of the subject - not just a gallery visitor any longer but a spectator, too - onto her/his mode of navigation of the space $\mathrm{s} / \mathrm{he}$ is in, and the way s/he will consume the art objects s/ he is going to encounter therein. As a matter of fact, by way of the design, disposition and dwelling processes I have discussed, the configuration of the space and the creation of a place on the one hand, and the approach of the subjects toward them on the other result profoundly altered. What does this mean in relation to art spaces? How does their setup, organization,

5 The first proposition to look at these moving image forms as fluid configurations is part of a conversation I had with Vinzenz Hediger (see De Rosa and Hediger 2016). 
pattern of use, and functions change when they are entered by the moving image? What experience do they favor? Is it an artistic experience, a filmic experience, none of them or both at once?

The disposition of the elements featured in art spaces, both structurally and in terms of setup, define the environment formally and functionally, that is to say, the regime of (audio-)vision offered to the visitors/spectators and its practicability. A modulation of the light conditions, for example, which has historically determined the difference between black box and white cube undergoes a sort of short circuit as the two are contained one in the other, paired side by side within the same context, or, again, mixed, their boundaries blurred (Leighton 2008; Fowler 2011; Bovier and Mey 2015; Uroskie 2014). Alongside this, and as a consequence, the focus of the attention and the ability of the image to hook the subject's eyes are played out differently than in the movie theater, having to open up the classic viewing scheme to a not necessarily frontal, not necessarily single-channel viewing situation conceived for a not necessarily static viewer. The distance that characterized the position between the spectator and the screen in the theatrical setting, albeit imposed, ${ }^{6}$ is altered as the classic apparatus is basically invested by a certain flexibility that reassembles its components in various different ways, which in turn implies a variable unveiling, closeness, and interaction with the dispositif ${ }^{7}$ itself. As a result, the psycho-motor stasis typical of the contemplation mode and the inquisitive attitude of the moving and interactive visitor are combined differently from time to time. A negotiation between the instances of cinema and those of art enabled by the design and disposition of the space turn the latter into a place for viewing and support the spectator/visitor in her/his experience of the space which will be practiced according to the design that the moving image has traced for her/him therein. In so doing, the trajectories crossing this space contribute

6 As many films have shown with exquisite meta-linguistic efficacy, in the movie theater we have a desiring spectator who is caught by the cinematic image on-screen. Her/his posture is notably one of stasis and his object of desire is kept away from her/him by a distance which in fact allows her/him seeing it on-screen. As Gabriele Pedullà states, "the movie theater forces the eye into a uniform" (2008, 129; my translation), that is to say the classic cinematic apparatus works on the basis of a "don't touch" discipline, which in turn exercises a strong appeal on the spectator. In the classic museum we encounter the same interdiction, where artworks are kept at a distance from the visitor. Differently from the cinema situation, the latter has the opportunity to browse around the gallery, to move and turn her/his desire to come closer, touch and perhaps become one with the artwork into a sort of flânerie allowing for a spatial prehension. A couple of key references in this regard are Strauven 2012; Van der Vall 2008.

7 I do not translate dispositif as apparatus as this would be reductive. For a similar use of the terms, please see Bellour 2012. 
to a dwelling experience that is offered by the moving image and that in effect re-organizes the space itself as a new, hybrid, reconfigured place bringing together cinema and art.

Echoing Brian O'Doherty (1999), David Joselit has described such a resulting form as "light cube" (2004), a crasis combining elements coming from both the cinematic and the museum spheres. For him, in fact, this context does not particularly activate a response in the viewer; on the contrary, systems such as CCTV and video projection alike, which are heavily employed in much video and installation art in the 196os and 1970s, would instead ultimately lead to a rather passive attitude:

Projection undermines one of the most progressive effects of the closedcircuit apparatus: its conceptualization of spectatorship as interactive, even if the interaction afforded is the arguably passive one of inserting one's body within a media circuit in order to view it relayed back to oneself, often in distorted form. Projection reintroduces a more conventionally theatrical mode of spectatorship in which the audience remains outside the media feedback loop rather than participating as actors within it. [...] Indeed, in this regard as well as in its adherence to the planarity of the gallery wall, video projection is as much heir to the traditions of modernist painting as it is successor to closed-circuit video. (Joselit 2004, 154)

In this view, the moving image entering a gallery space by way of video projections would "introduce figuration into the rigorously flat virtual space that had been associated with modernist painting" (Joselit 2004, 156). Joselit does not delve too much into the consequences of this genealogy he proposes in terms of the posture and attitude adopted by the spectators. If this implies a similarity between the posture of the visitor going to see a modernist painting exhibition and visiting any of the moving image works I have mentioned earlier, all of which technically include a video projection, I would suggest his argument is easily contestable. As a matter of fact, the position of the spectator/visitor embeds her/him in the same environment where the image is also present and embedded. Here, the latter designs the space and disposes it to be watched, while the former has indeed the agency to take on the invitation and practice that same space as a screening place, where s/he can most often browse and articulate her/his own experience of the space and the image. A recent experience, very much in line with the kind of closed-circuit video works Joselit relates to in his article, may serve as a good example. Recently I had the opportunity to experience Marta Minujín's Mesunda Reloaded 
(2019) at the New Museum in New York. Originally presented in 1965, the work in itself is an incredible circuit that takes visitors on a journey across eleven very different environments that basically reflect upon visuality, tactility, but also participation and media hyper-saturation in general; one of these environments is a two-storey path monitored by CCTV with vintage TV-sets placed along the space the visitor is invited to walk through, which broadcast the recording with a slight delay. The result is reminiscent of many famous antecedents: precisely as Joselit mentions, the visitor's image is relayed back to her/him and although the space does not really allow for a long stop, nor the journey s/he is supposed to walk through allows for any bold reactions at first, the effect is not one of passivity. The model of reference does not quite seem to be that which sees art and its public - or the film screen and the spectator - situated at a distance in a "arguably passive" interaction. Seeing my own image in Mesunda Reloaded certainly disciplined my spectatorial posture as much as it challenged its creative and interactive possibilities. The opportunity to react to the image arises and the narrative proposed by the artwork is scrutinized in search for a crack to penetrate it and subvert it, even just subtly or gently. In my case, I repeated the journey across that particular environment multiple times, going against the indications to move onto the next one; I did so pushed by the desire to observe better, to see where exactly the area recorded by the cameras was and how long the delay took, but also I was curious to check the orientation of the cameras and to search for a way to walk past them so that my body was caught in the most minimal way, or conversely, in its fullest. Discarding the model Joselit associates to closed-circuit camera works, my own experience is one of stimulation, of direct address which triggers a response. Well aware of not being a representative sample, it was however interesting to see that most of the visitors reacted to the camera and the moving image relaying the recording of their body back. This, to me, demonstrates the relevance of this reactive/interactive configuration based on the co-presence of the visitors' bodies and the image within the environment. In a way, this is a timely representation of what "postcinema" means and, more broadly, of our contemporary visual culture. The sense of a mutual contribution between artwork, environment, and visitors to produce the reality the latter were temporarily in was also rather strong, emphasizing the agency determining the experience of a constant writing and rewriting, interpretation and practice of space. In my own case, what was specifically stimulated was my media literacy; my symbolic and pragmatic encyclopedia as a screen media user kicked in quite automatically, inviting me to find ways to employ my skills and 


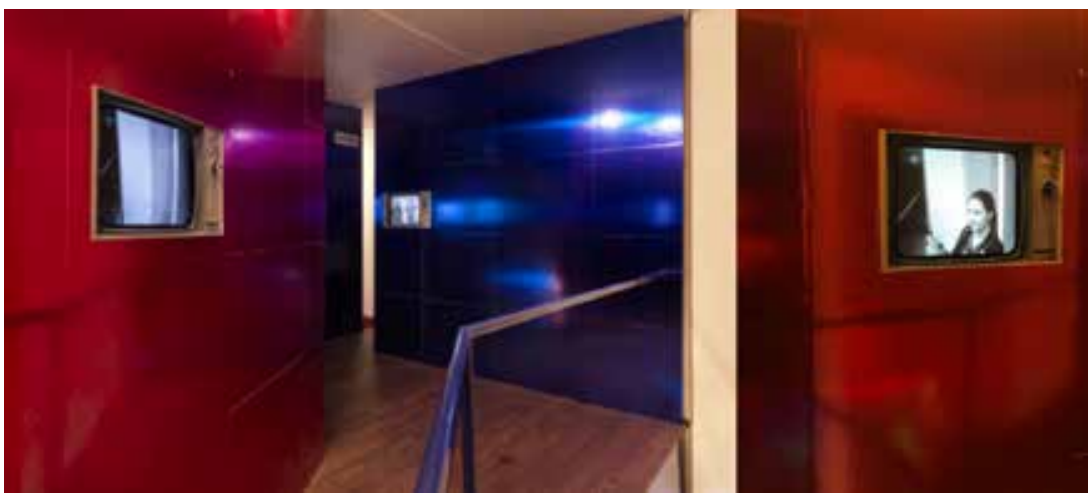

M. Minujín, Mesunda Reloaded (2019), New Museum, NYC. Photo credit: Author's personal archive

participate. As for many like me, this meant at least taking a picture of this experience and re-circulate it within a wider mediasphere (to which this reflection contributes as a paratext).

Minujín's work suggests that there is a deeper implication between subject, moving image, and space than what the notion of light cube promises. The configuration that results from the encounter and reciprocal action of these three elements assesses the sense of being there of the subject, her/ his sense of inhabiting the space alongside and through the image. I term this configuration space-image to stress the mutual interconnections and exchange among the elements involved. By way of the processes of design, disposition and dwelling, moving images are woven into the networked texture of the practices regulating the space they are in, making it practicable to the visitor/spectator. As Mesunda Reloaded shows, the negotiation between the elements at stake takes place in an organic fashion: the encounter between black box and white cube does not produce a third, possibly gray, area, but rather makes possible a space-image, that is, a configuration of experience which brings together space, image and subject, predicates their phenomenological co-presence and is based on their mutual, temporary influences on each other.

This active attitude of the visitor/spectator and the idea of spatialization of the moving image go hand in hand and characterize much of the experience of "post-cinema." A final example that tackles both aspects and shows their intertwined nature is the work by Milan-based collective Studio Azzurro. In particular, their sensitive environments represent a case in point when it comes to how the space-image in an artistic context looks like. One project in particular, SENSITIVE CiTY (SC hereafter), stands out in this instance, as it speaks both from a structural and a thematic perspective to the dynamics 

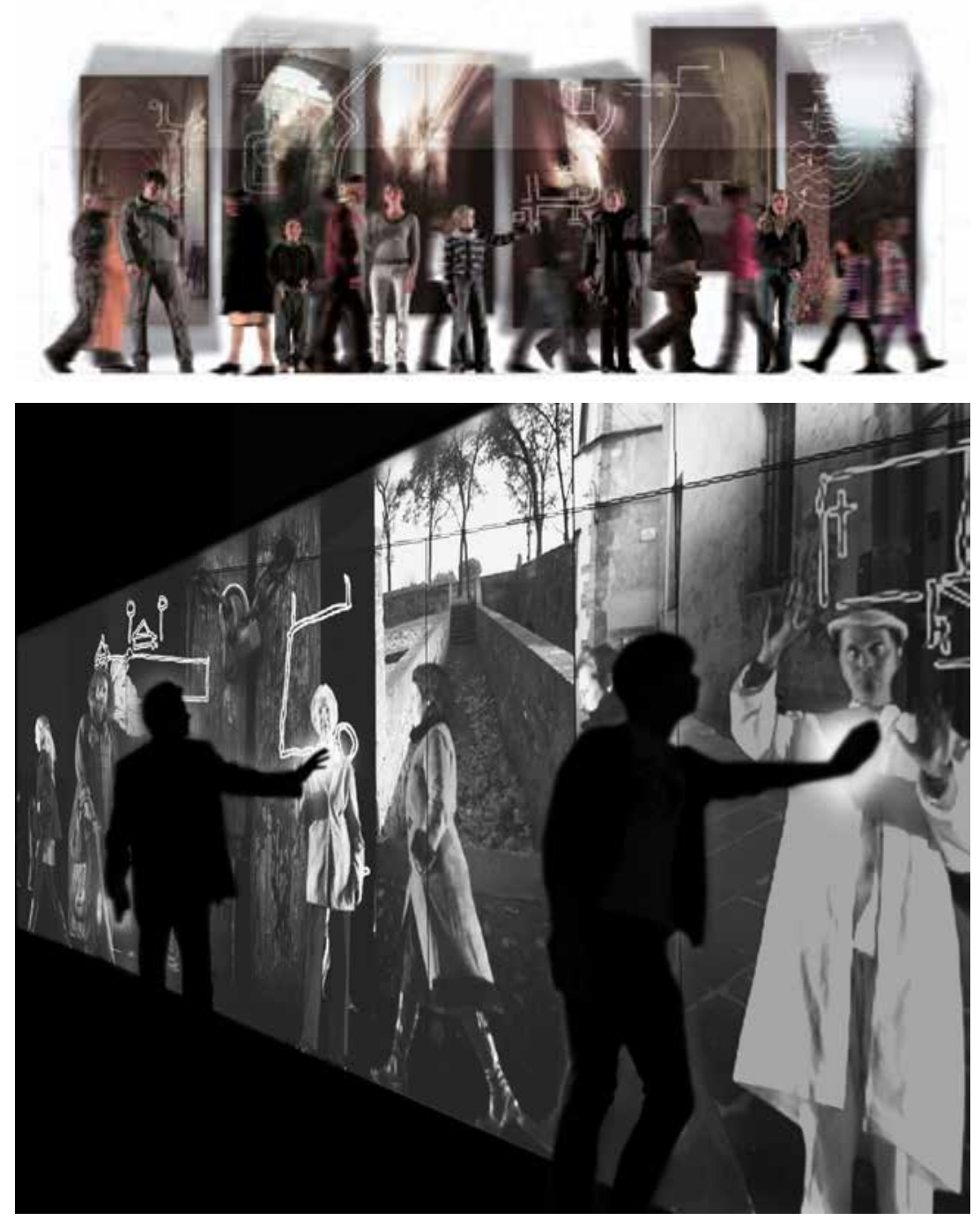

Studio Azzurro, Sensitive City, 2010. Photo credit: Studio Azzurro

of design, disposition, and dwelling that I described. In other words, the actual exhibition space where the installation is set up and presented on the one hand, and the narrative it develops on the other both revolve around and favor a critical reflection on spatiality and spatialization.

Centered on a novel interpretation of Thomas More's Utopia, SC also promotes the values of ideal communal living in space and with others. Instead of a centralized model planned by a visionary creator, however, it brings together in a unique narrative; the portrait of a series of mid-size 
Italian cities as they are experienced by their inhabitants. This is why SC is defined as a "counter-utopian city" (De Rosa 2010, 18). Embracing the perspective of the people living in Matera, Chioggia, Trieste, Syracuse, Spoleto, and Lucca allows the collective to enter into the depth of their features, histories, memories, to connect to specific spots of the narrated places that are eventually filmed, photographed, and mapped by the artists. The result is an exquisitely subjective geography of the places, in the Heideggerian sense of the term. To render these aspects, the objective of the installation was to offer an urban texture that is not structured a priori, but that instead takes shape and unfolds on the basis of the inhabitants' personal knowledge of the cities, by embedding in the representation their stories and affection for the corners of the cities they talk about, their drawings or sketches of their beloved place or fond childhood memory. Such a dense symbolical dimension speaks well to the kind of experience contemporary artistic moving images (as an example of "post-cinema") have to offer insofar as the freshness and live character of oral history, the transitory nature of mnestic processes as well as the placemaking and dwelling dynamics deriving from them well respond to the idea of space-image as a fluctuating, morphing configuration of experience. The sensitive environment translates this sense of ongoingness into a specific technological choice. Thanks to a system of sensors and large-scale touch screens, Studio Azzurro has redesigned the exhibition space disposing a set of complex devices which ensured the spatialization of the moving images across the space.

First presented at the World Expo 2010 in Shanghai, the installation was organized in three main areas: closer to the entrance is the photographic documentation of the cities explored in the project; next to these and moving more toward the bottom section of the pavilion are the portraits of the inhabitants of these cities who contributed to the project - space and subject, paired as essential ingredients of a dwelling recipe. Moving images soon join space and subject in the third section of the project, leading to the creation of a space-image. This last section is the bigger and core component of the project, and is located diagonally across the entire space. Projected on a long screen crossing the pavilion, moving images bring together the city and the people that the visitors had the opportunity to meet in the previous two areas of the installation. Not simple faces anymore, the inhabitants of the sensitive cities are now presented in their full body presence thanks to a life-size projection. They walk along the screen almost mingling with the visitors walking around the pavilion. In the artists' words: 
[the filmed subjects are] projected and triggered by interactive technological devices so that they become nodes of a reticular network and the core of our narrative structure. Each "story carrier" can be consulted, as he walks along, only if the visitor halts him or her with their hand. In which case they will turn towards them and begin their narration, which will last for as long as the hand will remain in contact with the projection surface. What we are suggesting is a very common relational gesture, the same we perform when we wish to stop someone in the streets to ask for directions. A simple gesture, yet endowed with a strong communicative symbolism which in this instance, in order to be complete, must persist to ensure that our virtual exchange is not cut short. (De Rosa 2010, 22)

The surface of the image does not only provide a space to make a story visible and watchable as any screen would classically do, but becomes a sensitive interface activating and maintaining alive the connection between the narrative and the public. The co-presence of the image and the subject in space, their being there is indeed independent one from the other, but their encounter is what constitutes the core of the project. This allows for a humanist reading: the fact that the installation is activated when characters and public actually come together suggests that not only they are there, but they are there for each other:

Listening to the stories couched in the sound of footsteps, in the instability of water, in the balance of wind, the surprise provided by darkness or the sudden appearance of light, means introducing one to think of a city in terms of the stories that are woven through it, the invisible shapes that permeate it, the emotional layers of which it is made [...] the quality of the relationships that are born out of it. (ibid.)

SC takes its cues from a relational map able to connect heterogenous elements. The result is a multicentric city whose exterior aspect moves and evolves as those inhabiting (the interviewed people) and crossing it (the viewers) practice its space. Metaphorically corresponding to the installation space, the narrated city is constituted by the images transitorily substantiating its views, spots, streets, and anecdotes throughout the exhibition space. This is why I find this installation perfectly exemplifies the concept of spatialization I presented above. And that is not all: captured by the moving image and thus translated into a graspable, perceptible material, narrative and relationships become the fibers of the sensitive city's texture. The resulting construction is based on multiple layers made of the drawings, 
annotations, video, and graphic images explaining what inhabiting the city means for the interviewed people. Located in a tridimensional space these elements spatialize the dwelling experience of the story carriers with the aim of eliciting a similar one in the viewers. This is precisely the main feature of Studio Azzurro's video-environments: SC offers the depiction of a city that literally explodes in the pavilion and fills it. The moving image makes room for itself across the exhibition space turning it into a place for viewing and dwelling, it works in other words as an organic material facilitating an interface, interaction, and appropriation of the space so as to allow a dynamic configuration to come to the surface. By means of the above-mentioned spatialization, this accounts for the emergence of an artistic space-image. The moment the visitors touch the screens the image is activated, the exhibition space is turned into a place of art and cinema, as a number of assemblages restructure the organization of the elements concurring with the disposition of the installation, and articulate the experiential materials of the interviewed people as a trigger to spark a new experience in the audience.

The concepts of encounter, touch, and interface play a key role in SC. Specifically, it is thanks to the latter that an opportunity to explicate their agency is given to the visitors - an agency which is an integral part of the symbolic value imbued in the installation, as it puts forth the principle of the encounter; an agency which is also very practically planned by the artists, as the encounter it promotes is technically possible via the touch. Subverting the golden rule of museum/cinema going, the public is requested to touch the moving image. The interface selected by Studio Azzurro requires the public to practice and participate, and hints at the materiality of a gesture - touching the screen - that alludes to an interactive quality which relies on a potentiality eventually becoming a real experience of exchange. Through such a gesture fiction and reality come together. Along the surface of the interface virtual and bodily qualities meet and the image finds its consistency anew. If, borrowing from Bourriaud, "any artwork might [...] be defined as a relational object, like the geometric place of a negotiation with countless correspondents and recipients" $(2002,26)$, then SC pushes this assumption further offering to the public a city which is primarily a place of encounter on both the diegetic and the extra-diegetic level because the very idea of encounter is celebrated, mixing the inputs of subjects, space, and image altogether.

In this view, the embedment of the subject within a texture of images dispersed throughout the space produces and enhances the sense of immersion, which represents the main formal characteristic of Studio Azzurro's sensitive environments. On a functional level, this translates 
in the installation's ability of enveloping the visitors and implicating them in a visual and tactile relationship with the moving image. SC offers emotional interstices and prehensive possibilities which overcome the spatial constraints of the representation appearing on-screen, activating a placemaking process which reconstructs the selected cities through the words, images, drawings, and notes by the inhabitants. These elements work as bridges connecting memories and stories to the present experience of the visitors, their desires to know more about what they see, their curiosity for some faraway places and some foreign faces that are now "spending their time" with them to explain about their places and sharing a space that becomes common ground. Additionally, the immersion and co-presence typical of sensitive environments such as SC favor a situation where the image does not imply addressing the subject with a direct interpellation (or inspires some sort of reaction and pragmatic engagement, as in my New Museum experience); rather, it cannot literally be activated without her/his participation. A mutual and constant exchange, epitomized by the touch that the hand of the visitor is invited to perform, shows how the employed interface implies a synaesthetic process: one has to touch in order to see. At the time of widespread touchscreens, the fingers of the public in contact with the skin of the moving image (Marks 200o) create the body of the sensitive city. Differently from the classic scheme typical of the museum as a collection to look at, the installation allows for a radically diverse experience, where the moving image works as a relational platform, an interface designed to create a room for dialogue, exchange, encounter. Hence the visitor ceases to be solely and purely a contemplating observer and becomes a player, meaning by that an actor that has a say in constructing the architecture of the space. If the artistic space-image describes the shapes experience can take in a place of art, here the engagement of the subject sits precisely in her/his active role in causing or being part of the event that generates the experience itself. The key process is the activation of the system that shows the city as it is taking shape. The installation space is therefore ever-changing, an ongoing assemblage of signs and images that emerge and dissolve. Conceptually, then, it is only by way of a complete superimposition of the physical gallery space and the symbolic fictional space that an appropriation of the narrated place is possible through a contact with the inhabitants of the city appearing on-screen. Such appropriation and inhabitation of the museum space, as if it was the city space, enables a construction of place: the visitors touch the screen and see the urban environment coming into existence, they listen to the narrative about it and are involved, invited, implicated in it. 
In this sense, the itineraries and the images describing the city contribute to both the representation of the real Italian cities they refer to and the constructed texture of the counter-utopic, unique, sensitive city that serve as organic material constituting the space-image. The video-testimonies, the photographic portraits, the maps appearing next to the inhabitants who share a story or an itinerary throughout their place are visual and cinematic tools concurring with a relational configuration, guiding the visitors along the paths documented and captured by Studio Azzurro's movie camera. Analyzing this correspondence closer, it is possible to see a process of deixis: the exploration of the cities narrated by the inhabitants is continued by the visitors in the exhibition space, a connection between represented and practiced dimensions, between fictional and physical space, occurs and it is here that dwelling becomes a shared horizon of experience.

As Alison Butler has efficaciously argued, processes like the ones we encounter in SC are the effect of a "deictic turn" (2010). I shall posit this is to be considered in relation to the spatial turn in film studies I have mentioned earlier, which served as methodological premise of these pages. Talking about "post-cinema" is talking about the result of these processes, whose ultimate outcome to me is an experience similar to that elicited by SC that I have tried to describe. In this experience the text can be fragmented and vary, the context does not simply work as a container but substantially contributes to the content of the piece as much as the moving images do. The configuration they take, finally, is established on the basis of a highly variable pattern, which may include various degrees of activity and interactivity - cognitive, perceptual, and intellectual alike - on the part of the public. All of this mirrors a situation where certainly the processes of design, disposition and re-disposition, and finally the chance of dwelling represent a complexification of previous canons, models, and apparatuses but also open up the precious opportunity to be there, with the moving image, for the moving image, and to use it to re-affirm its relational potentialities and creative power. Which is ours too.

\section{References and Further Reading}

Aumont, Jacques. 2012. Que reste-t-il du cinéma? Paris: Vrin.

Bellour, Raymond. 2012. Between-the-images. Zurich:JRP/Ringier.

Bourriaud, Nicholas. 2002. Relational Aesthetics. Dijon: Les Presses du réel.

Bovier, François, and Adeena Mey. 2015. Exhibiting the Moving Image: History

Revisited. Zurich:JRP/Ringier. 
Butler, Alison. 2010. "A Deictic Turn: Space and Location in Contemporary Gallery Film and Video Installation." Screen 51, no. 4: 305-323.

Casetti, Francesco. 2015. The Lumière Galaxy: Seven Keywords for the Cinema to Come. New York: Columbia University Press.

Chateau, Dominique, and José Moure, eds. 2016. Screens: From Materiality to Spectatorship - A Historical and Theoretical Reassessment. Amsterdam: Amsterdam University Press.

Cherchi Usai, Paolo. 2001. The Death of Cinema: History, Cultural Memory and the Digital Dark Age. London: British Film Institute.

Connolly, Maeve. 2009. The Place of Artists Cinema: Space, Site and Screen. Bristol: Intellect.

Cowie, Elizabeth. 2009. "On Documentary Sounds and Images in the Gallery." Screen 50, no. 1: 124-134.

Decandia, Lidia. 2010. “Sensitive City." In Studio Azzurro, Sensitive City. Milan: Scalpendi.

De Rosa, Miriam. 2013. Cinema e postmedia: Iterritori del filmico nel contemporaneo. Milan: Postmedia books.

De Rosa, Miriam, and Vinzenz Hediger. 2016. "Post-what? Post-when? A Conversation on the 'Posts' of Post-media and Post-cinema." Cinéma \& Cie, no. 26-27: 9-20.

Foster, Hal, Malcolm Turvey, Chrissie Iles, George Baker, Matthew Buckingham, and Anthony McCall. 2003. “The Projected Image in Contemporary Art.” October 104 (Spring): 71-96.

Fowler, Catherine. 2004. "Room for Experiment: Gallery Films and Vertical Time from Maya Deren to Eija Liisa Ahtila." Screen 45, no. 4: 324-343.

-. 2011. "Remembering Cinema Elsewhere: Introspections and Circumspection in the Gallery Films." Cinema Journal 2, no. 51: 26-45.

Friedberg, Anne. 2000. Window Shopping: Cinema and the Postmodern. Berkeley, CA: University of California Press.

Gaudreault, André, and Philippe Marion. 2015. The End of Cinema? A Medium in Crisis in the Digital Age. New York: Columbia University Press.

Harbord, Janet. 2002. Film Cultures. London: Sage.

Heidegger, Martin. 1971. "Poetically Man Dwells." In Poetry, Language, Thought, 221-239. New York: Harper and Row.

—. 1993. "Building, Dwelling, Thinking." In Basic Writings, 343-363. New York: Harper Collins.

Joselit, David. 2004. “Inside the Light Cube: Pierre Huyghe's Streamside Day Follies and the Rise of Video Projection." Artforum 42, no. 7 (March): 154-159.

Kim Jihoon. 2016. Between Film, Video, and the Digital: Hybrid Moving Images in the Post-Media Age. New York: Bloomsbury. 
Krauss, Rosalind E. 1999a. "Reinventing the Medium." Critical Inquiry 25, no. 2 (Winter): 289-305.

- 1999b. A Voyage on the North Sea. Art in the Age of the Post-medium Condition. New York: Thames \& Hudson.

Leighton, Tanya, ed. 2008. Art and Moving Image: A Critical Reader. London: Tate/ Afterall.

Marchessault, Janine, and Susan Lord, eds. 2007. Fluid Screens, Expanded Cinema. Toronto, Buffalo, London: University of Toronto Press.

Marks, Laura U. 2000. The Skin of the Film: Intercultural Cinema, Embodiment, and the Senses. Durham and London: Duke University Press.

—. 2012. "Immersed in the Single Channel: Experimental Media from Theater to Gallery." Millennium Film Journal, no. 55: 14-23.

O’Doherty, Brian. (1976) 1999. Inside the White Cube: The Ideology of the Gallery Space. Berkeley and Los Angeles: University of California Press.

Pedullà, Gabriele. 2008. In piena luce: Inuovi spettatori e il sistema delle arti. Milan: Bompiani.

Rhodes, John David, and Elena Gorfinkel, eds. (2001) 2011. Taking Place: Location and the Moving Image. Minneapolis: University of Minnesota Press.

Rodowick, David N. 2008. The Virtual Life of Film. Cambridge, MA: Harvard University Press.

Rosa, Paolo. 2010. Sensitive City. In Studio Azzurro, Sensitive City. Milan: Scalpendi. Sobchack, Vivian. 2016. "From Screen-Scape to Screen-Sphere: A Meditation in Medias Res." In Screens: From Materiality to Spectatorship - A Historical and Theoretical Reassessment, edited by Dominique Chateau and José Moure, 157-175. Amsterdam: Amsterdam University Press.

Strauven, Wanda. 2012. "Early Cinema's Touch(able) Screens: From Uncle Josh to Ali Barbouyou." NECSUS. European Journal of Media Studies, no. 2. Accessed, September 9, 2019. https://necsus-ejms.org/early-cinemas-touchable-screensfrom-uncle-josh-to-ali-barbouyou/.

Uroskie, Andrew. 2014. Between the Black Box and the White Cube: Expanded Cinema and Postwar Art. Chicago and London: University of Chicago Press.

Van de Vall, Renée. 2008. At the Edges of Vision: A Phenomenological Aesthetics of Contemporary Spectatorship. London and New York: Routledge. 


\section{About the Author}

Miriam De Rosa is Assistant Professor of Research in the Centre for Postdigital Cultures at Coventry University. She is the author of Cinema e postmedia (2013), the editor of Gesture (2019), and the coeditor of Post-what? Post-when? Thinking Moving Images Beyond the Postcinema Condition (2017) and Cinema and Domestic Space (2020). As an independent curator, her most recent projects comprise Desktop Cinema (2017), Film | Creativity | Resistance (2019), and I Am the Mace - Kelly Gallagher's Films (with G. de Cuir Jr. 2019). 